\title{
Laser applications in thin-film photovoltaics
}

\author{
R. Bartlome · B. Strahm • Y. Sinquin • A. Feltrin • \\ C. Ballif
}

Received: 14 October 2009 / Revised version: 24 November 2009 / Published online: 14 January 2010

(C) Springer-Verlag 2010

\begin{abstract}
We review laser applications in thin-film photovoltaics (thin-film $\mathrm{Si}, \mathrm{CdTe}$, and $\mathrm{Cu}(\mathrm{In}, \mathrm{Ga}) \mathrm{Se}_{2}$ solar cells). Lasers are applied in this growing field to manufacture modules, to monitor Si deposition processes, and to characterize opto-electrical properties of thin films. Unlike traditional panels based on crystalline silicon wafers, the individual cells of a thin-film photovoltaic module can be serially interconnected by laser scribing during fabrication. Laser scribing applications are described in detail, while other laserbased fabrication processes, such as laser-induced crystallization and pulsed laser deposition, are briefly reviewed. Lasers are also integrated into various diagnostic tools to analyze the composition of chemical vapors during deposition of Si thin films. Silane $\left(\mathrm{SiH}_{4}\right)$, silane radicals $\left(\mathrm{SiH}_{3}, \mathrm{SiH}_{2}\right.$, $\mathrm{SiH}, \mathrm{Si}$ ), and $\mathrm{Si}$ nanoparticles have all been monitored inside chemical vapor deposition systems. Finally, we review various thin-film characterization methods, in which lasers are implemented.
\end{abstract}

\section{Introduction}

The terrestrial photovoltaic (PV) market has been dominated by the wafer-based crystalline silicon (c-Si) technology ever since the mid 1970s [1]. In the past decade, thin-film (TF) photovoltaics has attracted a growing interest both in academic and industrial environments. This has translated into a continuous gain of market share since 2004 (12.5\% in 2008)

R. Bartlome $(\bowtie) \cdot$ B. Strahm · Y. Sinquin · A. Feltrin · C. Ballif Institute of Microengineering (IMT), Photovoltaics and Thin Film Electronics Laboratory, Ecole Polytechnique Fédérale de Lausanne (EPFL), Rue A.-L. Breguet 2, 2000 Neuchâtel, Switzerland

e-mail: richard.bartlome@epfl.ch and a constant increase of TF production volume (reaching a record-breaking $1.0 \mathrm{GW}_{\mathrm{p}}$ in 2008) [2]. The backbone of these TF technologies relies on hydrogenated amorphous silicon (a-Si:H), hydrogenated microcrystalline sili$\mathrm{con}^{1}$ ( $\left.\mu \mathrm{c}-\mathrm{Si}: \mathrm{H}\right)$, cadmium telluride $(\mathrm{CdTe})$, or $\mathrm{Cu}(\mathrm{In}, \mathrm{Ga}) \mathrm{Se}_{2}$ (CIGS) semiconducting materials. Despite lower efficiencies $\left(\leq 12 \%\right.$ up to date ${ }^{2}$ ), commercial TF PV modules offer many advantages with respect to their wafer-based c$\mathrm{Si}$ counterparts. Besides evident lower raw material costs, materials with different bandgaps can be engineered and stacked to exploit a larger part of the solar spectrum, thereby increasing the efficiency of the TF PV device. Moreover, films are deposited on inexpensive substrate materials, such as glass. Inexpensive and flexible modules may even be fabricated on metallic or plastic foils. Finally, large areas $\left(>1 \mathrm{~m}^{2}\right)$ can be processed because (a) TF deposition facilities are usually scalable, and (b) the individual PV cells of a large module can be serially interconnected without the need of time-consuming wiring. To achieve this task, three patterns (p1, p2, p3) are micromachined during fabricationprincipally by laser scribing. In this respect, lasers have become key-components in the production of TF PV modules.

Various applications are securing a bright future for lasers in TF photovoltaics. Laser scribing along with other laser processes for TF photovoltaics are reviewed under Sect. 2. Lasers are also integrated into various diagnostic tools to analyze deposition processes of Si thin films. Such applications are reviewed under Sect. 3. Finally, in the development stage of PV cells, lasers are applied in several TF characterization methods, reviewed under Sect. 4.

\footnotetext{
${ }^{1}$ This material is also known as hydrogenated nanocrystalline silicon (nc-Si:H).

${ }^{2}$ Total-area efficiency under standard test conditions.
} 


\section{Laser processes for TF photovoltaics}

Among laser processes for TF photovoltaics, only laser scribing systems hardly suffer any competition from other techniques. Laser scribing systems have the ability to machine narrow patterns on a wide range of materials in a selective, precise, and cost-effective manner. It is a noncontact process, meaning that the mechanical stress applied on the micromachined layers is limited. Unlike the tip of a mechanical scriber that suffers mechanical wear [3], a laser scriber-when powered by a diode-pumped solid state laser (DPSSL)—can operate continuously for over 10000 hours. Other laser processes, such as pulsed laser deposition and laser-induced crystallization, have not yet penetrated the TF PV market.

\subsection{Laser scribing}

As mentioned above, the serial monolithic interconnection of TF solar cell can be achieved by scribing three patterns during fabrication, a process developed by Nakano et al. [4]. The films are patterned after each layer deposition, as pictured in Fig. 1. The end-result is a PV module comprising
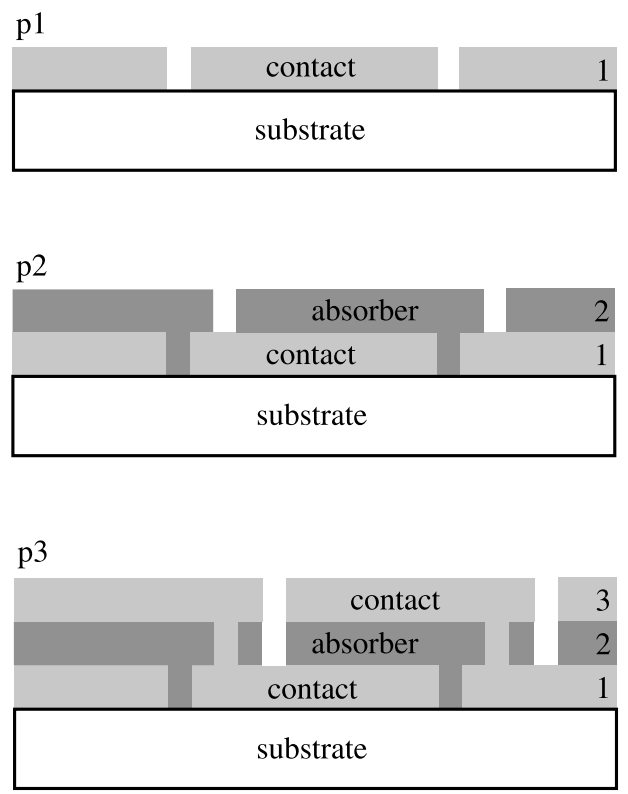

Fig. 1 Schematic view of the p1, p2, and p3 processes. The layers are numbered in the order in which they are deposited. They are micromachined by laser ablation, an established material removal process that has been extensively studied in literature $[8,16]$. For this purpose, a short (ns) or ultrashort ( $\mathrm{ps}$ or fs) pulsed laser beam is focused on the substrate. The repetition rate of the laser is synchronized to the feed rate of the workpiece. The first and second layers are micromachined during the $\mathrm{p} 1$ and $\mathrm{p} 2$ process, respectively. During the $\mathrm{p} 3$ process, the pulse energy is usually deposited in the second layer. The overlying volume is then removed by explosive ablation (caused by the pressure build-up in the second layer). The first layer must remain unaffected by the $\mathrm{p} 2$ and $\mathrm{p} 3$ processes serially interconnected strip-shaped solar cells. The number of cells and their width determine the ultimate open-circuit voltage and short-circuit current of the finished module, respectively. The scribed lines are narrow $(20-100 \mu \mathrm{m})$ and closely aligned to each other in order to minimize the socalled dead area between the first and third patterns. The ideal cell width, of the order of $10^{-2} \mathrm{~m}$, is a trade-off between the dead area and ohmic losses in the contacts. Furthermore, the ideal width of the p1 line is a trade-off between the dead area and the electric isolation between the first deposited contact of neighboring cells [5].

The laser setup depends on whether the films have been stacked in a substrate or superstrate configuration.

In the superstrate configuration, the substrate is transparent and facing the incoming sunlight. As pictured in Fig. 2, the first deposited layer is a transparent conductive oxide (TCO), followed by an absorber layer, and a back contact/reflector. Depending on the TF PV technology, the absorber can be a CdS/CdTe heterojunction, an a-Si:H p-i-n junction, or a micromorph tandem structure (a-Si:H/ $\mu \mathrm{c}-\mathrm{Si}: \mathrm{H})[6,7]$. The front TCO layer is scribed by infrared or ultraviolet laser radiation ( $\mathrm{p} 1$ process). The industrial workhorses for this task have been Q-switched (ns pulses) DPSSLs emitting at $1064 \mathrm{~nm}$ or $355 \mathrm{~nm}$ (third harmonic), respectively. The active medium of these lasers is a neodymium-doped crystal (Nd:YAG or $\mathrm{Nd}: \mathrm{YVO}_{4}$ ). A frequency-doubled DPSSL emitting at $532 \mathrm{~nm}$ typically performs the $\mathrm{p} 2$ and $\mathrm{p} 3$ processes. During all three processes, the laser fluence on the workpiece is optimized in order to work within an ideal range situated above the ablation threshold. The threshold fluence of various relevant materials have been measured by Compaan et al. [8], whereas the pulse shape and the pulse overlap in TF Si technologies are discussed by Haas et al. [9, 10]. Molpeceres et al. compare the 1 process at $1064 \mathrm{~nm}$ and $355 \mathrm{~nm}$ using a tin-doped
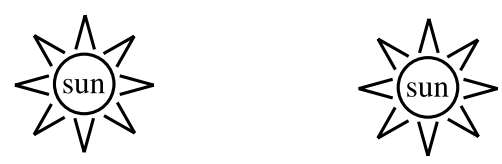

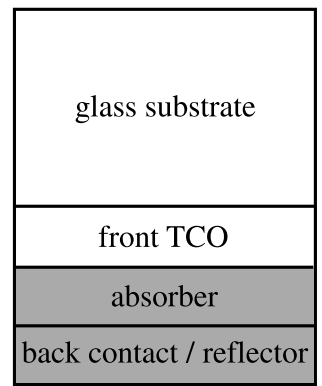

a

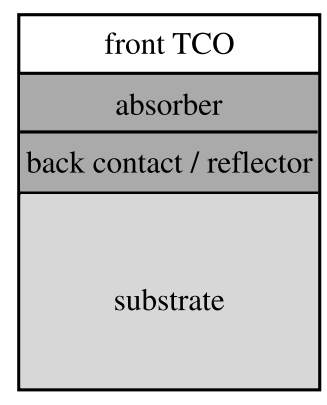

b
Fig. 2 Schematic view of a TF PV cell in the superstrate (a) and substrate (b) configuration 
indium oxide as front TCO [11, 12]. In CdTe solar cells, all three processes can be in principle performed at $1064 \mathrm{~nm}$, as the ablation threshold of CdTe at this wavelength - unlike a-Si:H or $\mu \mathrm{c}-\mathrm{Si}: \mathrm{H}-\mathrm{is}$ lower than the ablation threshold of the TCO [8, 13]. Irrespective of the TF technology, the laser beam can be directed towards the PV module from the glassside. In this manner, the ablated material is easily withdrawn from the opposite side. Furthermore, material ejectionwhich begins in a ps timescale-does not interact with the ns-long laser pulse.

In the substrate configuration, the PV module is fabricated in reverse order, i.e., from back to front with respect to sunlight (Fig. 2). This configuration is chosen to fabricate CIGS solar cells or TF PV cells on opaque substrates, such as steel and plastic foils. If the substrate is conductive, the individual PV cells may be monolithically interconnected by laser scribing, provided that an insulating layer is deposited first. Irrespective of the substrate material, the p2 and p3 processes must be conducted from the layer side. The $\mathrm{p} 2$ and p3 patterns of CIGS solar cells, which use molybdenum as a back contact, are often machined with mechanical scribers, but laser scribing systems are progressively taking over the task. To avoid molybdenum damage during laser processing of the overlaying layers, ultrashort laser pulses (ps or fs) are required $[14,15]$. It is well known that the thermal dissipation beyond the volume that is ablated is then widely suppressed [16, 17].

In contrast to the smooth and hard surface of a glass substrate, a soft plastic foil is difficult to structure with a mechanical tool without causing damage. Furthermore, ns pulses have not been able to produce well-defined laser scribing grooves in flexible solar cells that incorporate metallic back reflectors such as silver or aluminum. As an alternative to removing the absorbing film entirely, analogous to mechanical or laser scribing, laser processes have been developed to locally transform the absorber into a conductive channel $[18,19]$. These interconnection schemes, which replace the $\mathrm{p} 2$ process, are conducted at laser fluences below the ablation threshold.

Large industrial laser scribing systems, recently reviewed [20], process several lines simultaneously. The underlying concepts for beam delivery are further discussed in [21].

\subsection{Laser-induced crystallization}

Polycrystalline thin films on low-cost glass substrates are expected to combine the high efficiencies of wafer-based cSi PV cells with the low manufacturing cost of TF Si PV cells. Different approaches have been investigated to overcome the conflicting requirement of a high temperature for crystallization and a low temperature for preventing damage on the low-cost glass substrate [22, 23]. Solid-phase crystallization of Si-coated glass has been the most successful approach so far in terms of device performance (10.4\% efficiency on a $10 \mathrm{~cm} \times 10 \mathrm{~cm}$ mini-module) $[6,24]$, but the process requires annealing at $600^{\circ} \mathrm{C}$ for several hours. Other crystallization methods have achieved higher efficiencies, however it must be emphasized that these processes require high-temperature-resistant substrates [22]. Laserinduced crystallization appeared once to be the only approach capable of forming polycrystalline Si films on commercially available glass substrates at low temperatures $\left(<220^{\circ} \mathrm{C}\right)$. The technique simply consists in heating amorphous $\mathrm{Si}$ with ns or $\mu$ s pulses above the melting point of $\mathrm{Si}$ (at fluences below the ablation threshold). During the rapid melting and resolidification of amorphous $\mathrm{Si}$, the substrate does not have time to heat up. The process may be followed by epitaxial thickening. Substantially large lateral grain sizes $(>10 \mu \mathrm{m})$ have been reported using a $\mu$ s-pulsed $\mathrm{Ar}^{+}$laser system (cw beam modulated with an acoustooptic modulator) [25]. Most studies have been conducted with excimers laser and were reviewed by Adikaari et al. [26]. In spite of all these efforts, reports of device-grade material are still lacking. In the context of PV cells, early industrial investigations also seem to have been abandoned [27].

Recently, Nayak et al. reported nanocrystalline Si material following femtosecond-laser-induced crystallization of a-Si:H [28]. Nevertheless, the sub-bandgap absorption is so high that the material seems to have lost its semiconducting properties. Despite the amount of structural defects, which for the time being prohibits PV applications, the process produces remarkable light-trapping microstructures at the surface. Similar effects have been studied extensively by Her et al. on c-Si wafers [29].

\subsection{Pulsed laser deposition}

Deposition techniques constitute a vast technological field. In pulsed laser deposition (PLD), the output of a pulsed laser is focused onto a target material mounted inside a vacuum chamber. The ejected plasma plume expands away and impinges on the substrate of interest. The properties of the deposited film generally depend on the substrate temperature, the laser-target-substrate geometry, the presence of a background gas in the chamber, and several laser parameters (wavelength, pulse duration, fluence). PLD has been a competitive tool to grow thin films with well-defined complex stoichiometries. Photovoltaic-relevant materials (e.g., $\mathrm{ZnO}, \mathrm{CdTe}, \mathrm{ZnS}$ ) have also been grown by PLD [30-32]. The chances of this technique entering the PV market, however, remain poor as upscaling is difficult. Furthermore, the ejection of macroparticles prevent many practical applications in photovoltaics [33]. 
Table 1 Laser-based techniques that have been implemented in PECVD systems to study silane-containing plasmas

\begin{tabular}{llll}
\hline Technique & Laser & Detected species & References \\
\hline Infrared absorption spectroscopy & $\mathrm{Pb}$-salt, $\mathrm{QCL}$ & $\mathrm{SiH}_{\mathrm{SiH}}, \mathrm{SiH}_{4}$ & [35-37, 43] \\
Cavity ring-down spectroscopy & $\mathrm{Dye}(\omega, 2 \omega)$ & $\mathrm{Si}, \mathrm{SiH}, \mathrm{SiH}_{3}, \mathrm{Si}$ nanoparticles & {$[34,49-51,93]$} \\
Laser-induced fluorescence & $\mathrm{Dye}(\omega, 2 \omega)$ & $\mathrm{Si}, \mathrm{SiH}, \mathrm{SiH}_{2}$ & {$[52,53,55]$} \\
Laser light scattering & $\mathrm{He}-\mathrm{Ne}, \mathrm{Ar}^{+}$, & $\mathrm{Si} \mathrm{nanoparticles}$ & {$[56-64]$} \\
& $\mathrm{Nd}: \mathrm{YAG}(\omega, 2 \omega, 3 \omega, 4 \omega)$ & & Si nanoparticles \\
Laser-induced particle explosive evaporation & $\mathrm{XeCl}^{*}, \mathrm{Nd}: \mathrm{YAG}$ & &
\end{tabular}

\section{Laser diagnostics during deposition of Si thin films}

In this section, we review how lasers are applied as diagnostic tools during deposition of Si thin films. Si deposition usually takes place in chemical vapor deposition (CVD) reactors. The most common precursor gases of Si thin films are silane $\left(\mathrm{SiH}_{4}\right)$ and hydrogen $\left(\mathrm{H}_{2}\right)$. Silane may either be dissociated by catalytic reaction or electron impact, as it is predominantly the case in hot-wire CVD (HWCVD) and plasma-enhanced CVD (PECVD), respectively. In Table 1, we summarize laser diagnostic tools that have been implemented in PECVD systems, which are by far the most common. Silane and its radicals have been monitored in such systems by fluorescence and absorption spectroscopy. These laser-based techniques are reviewed in Sect. 3.1. Under certain process conditions, the dissociation of silane in chemical reactors leads to the formation of nanoparticles. The latter can be detected by laser light scattering or laser-induced explosive evaporation. Both techniques are reviewed in Sect. 3.2.

\subsection{Laser spectroscopy}

Laser spectroscopy-as well as other spectroscopic techniques such as optical emission spectroscopy, mass spectroscopy, or Fourier transform infrared spectroscopy (FTIR) - have all been applied as plasma diagnostic tools. Their objective is to measure the density of molecules and radicals present in the plasma, which is of utmost importance to understand the relation between the plasma composition and the properties of deposited films.

The importance of a silane radical with respect to the growth of Si films is assessed on the basis of its density in the plasma and its surface reaction probability. For conditions under which device-grade material is grown, it is found that $\mathrm{SiH}_{3}$ is the most abundant radical in PECVD reactors [34]. Radicals with a higher Si hydrogenation are, however, less reactive. Overall, $\mathrm{SiH}_{3}$ is believed to be the most significant film growth precursor [34, 35].

\subsubsection{Infrared absorption spectroscopy}

By 1986 diode laser spectrometers had already detected $\mathrm{SiH}$ and $\mathrm{SiH}_{3}$ in electric discharges [36, 37]. In these early studies, a cryogenically-cooled lead-salt laser was typically coupled into a multipass optical setup positioned along a discharge tube. Multipass arrangements, mostly of the White [38] or the Herriott type [39, 40], were used to increase the absorption path length by several meters, thereby enhancing the sensitivity of the detection scheme [41].

Further studies have been mainly dedicated to better understand the relevance of $\mathrm{SiH}_{3}$ to the film growth mechanism. Sumiyoshi et al. [42] measured the $\mathrm{SiH}_{3}$ density in a phenylsilane discharge. The latter was ignited between two cylindrical electrodes mounted in a glass tube. The parent gas was phenylsilane rather than silane to avoid possible interferences with silane absorption lines. The multimode diode laser was tunable around $4.5 \mu \mathrm{m}$, where $\mathrm{Si}-\mathrm{H}$ stretching vibrations of $\mathrm{SiH}_{3}$ take place ( $\nu_{3}$ band). Itabashi et al. [35] measured the $\mathrm{SiH}_{3}$ density profile between the two electrodes of a parallel-plate reactor. From the infrared absorption at $720 \mathrm{~cm}^{-1}$ in $\mathrm{SiH}_{4}-\mathrm{H}_{2}$ discharges, they deduced a contribution of $\mathrm{SiH}_{3}$ to the film growth of about $60 \%$.

More recently, the authors have shown that silane $\left(\mathrm{SiH}_{4}\right)$ itself can be monitored in the pumping line of a CVD reactor [43]. Despite the low pressure in the pumping line (lower than the 1-6 mbars maintained in the reactor), the silane density was sufficient to be measured in a single-pass arrangement with a Peltier-cooled quantum cascade laser emitting around $4.6 \mu \mathrm{m}$. This wavelength range is particularly suitable, as it features intense roto-vibrational absorption lines of the $v_{3}$ band of $\mathrm{SiH}_{4}$. In the absence of powder particles, the authors could monitor in situ the TF Si deposition rate. Time-resolved silane density measurements inside the CVD reactor is a subject of current research.

\subsubsection{Cavity ring-down (CRD) spectroscopy}

Monitoring radicals in chemical reactors is a challenging task because (a) radical densities are low, (b) the optical path length available in laboratory-scale reactors rarely exceeds 
$1 \mathrm{~m}$, and (c) reactor environments are harsh (high temperatures, aggressive chemicals). To enhance the sensitivity of a detection scheme, the effective path length may be increased by using a cavity ring-down (CRD) setup [41, 44, 45] or a multipass arrangement [38-41]—as mentioned above. Originally designed to measure precisely the high reflectivity of laser mirrors [46-48], the CRD technique is known today as a sensitive trace-gas detection scheme [41]. The technique consists in coupling a laser pulse into a high-finesse cavity formed by two highly reflective dielectric mirrors $(R>99.99 \%)$ that are facing each other. Every time that the light is reflected back and forth inside the cavity, a small fraction of the light leaks out of the cavity. Instead of measuring the absolute value of the light intensity leaking out of the cavity, one determines the light intensity decay time. The higher the absorption inside the cavity, the smaller the measured decay time. The CRD technique is intrinsically insensitive to laser power fluctuations. A further advantage over other spectroscopic techniques is that the effective absorption path length of a CRD setup is extremely long (several kilometers).

Silane-containing discharges have been investigated by only a handful of CRD experiments. Exclusively designed in the visible range up to date, CRD cells have been coupled with the fundamental beam or the second harmonic of Nd:YAG-pumped dye lasers.

Kessels et al. [49] performed CRD measurements across an expanding thermal plasma (ETP). They were able to determine the absolute density of $\mathrm{Si}$ and $\mathrm{SiH}$ radicals in an $\mathrm{Ar}-\mathrm{H}_{2}-\mathrm{SiH}_{4}$ plasma. The Si density, of the order of $10^{15} \mathrm{~m}^{-3}$, was about 2 orders of magnitude lower than the $\mathrm{SiH}$ density. By means of a simple chemical and surface reaction model, they deduced that $\mathrm{Si}$ and $\mathrm{SiH}$ radicals contribute to the film growth mechanism by about $0.2 \%$ and $5 \%$ only, respectively. From time-resolved CRD measurements in the afterglow of an ETP, Hoefnagels et al. [34] showed that $\mathrm{Si}$ radicals have a higher gas-phase reactivity and, consequently, a shorter lifetime than $\mathrm{SiH}_{3}$ radicals. Hoefnagels et al. also derived a surface reaction probability of $>0.95$ and 0.3 for $\mathrm{Si}$ and $\mathrm{SiH}_{3}$, respectively. Finally, they demonstrate that $\mathrm{SiH}_{3}$ is by far the most important film growth precursor in ETPs.

Under many plasma conditions used to deposit devicegrade material, CRD measurements in the visible are influenced by the light scattering and absorption of Si nanoparticles. Nagai et al. [50] recently reported that the cavity loss in the 220-280 nm wavelength range is not only due to the expected $\tilde{A}^{2} A_{1}^{\prime} \leftarrow \tilde{X}^{2} A_{1}$ broadband transition of $\mathrm{SiH}_{3}$. In fact, a three-step mechanism was identified. In the first step directly following the discharge break-down, no extra cavity loss is measured. In the second step, the contribution of silicon particles increases rapidly as a function of time, and in the third step the cavity loss due to particles tends to reach a plateau. These three steps can be associated to silicon nanocluster formation, cluster agglomeration, and agglomeratesize growth by chemical sticking.

Grangeon et al. [51] had already applied CRD spectroscopy to detect $\mathrm{Si}$ particles in a large-area industrial parallel-plate reactor. In their work, they pointed out the importance of reactor conditioning prior to CRD measurements to avoid contamination of the mirror surfaces during the discharge. Mirror contamination can either come from direct film deposition or from chemical adsorption, e.g., of water. The contamination of CRD mirrors results in an unknown change of the mirror reflectivity and, consequently, in a change of the apparent extinction coefficient.

To summarize, the density and lifetime of $\mathrm{Si}, \mathrm{SiH}$, and $\mathrm{SiH}_{3}$ radicals were determined by CRD spectroscopy. Gasphase reaction rates and surface reaction probabilities could be derived from these measurements. Moreover, it was shown that CRD spectroscopy can detect the onset of Si particle formation.

\subsubsection{Laser-induced fluorescence spectroscopy}

The detection of $\mathrm{Si}, \mathrm{SiH}$, and $\mathrm{SiH}_{2}$ has been reported in several laser-induced fluorescence (LIF) studies. The latter often require advanced acquisition schemes to discriminate against stray light emitted inside the CVD reactor. Some schemes average a large number of fluorescence pulses with gated integrators, and other perform afterglow measurements, where the LIF signal is acquired just after the extinction of a glow discharge.

Roth et al. [52] measured the Si density profile between the symmetric electrodes of a PECVD system. An Nd:YAGpumped frequency-doubled dye laser tuned at $251.43 \mathrm{~nm}$ excited the $\mathrm{Si}$ radicals during a $\mathrm{SiH}_{4}-\mathrm{Ar}$ discharge. The $\mathrm{Si}$ fluorescence was measured at $252.85 \mathrm{~nm}\left(4 s^{3} P_{1}^{0} \rightarrow 3 p^{2}{ }^{3} P_{2}\right.$ transition). These studies showed that the sheaths do not have any $\mathrm{Si}$ atoms, and that the $\mathrm{SiH}_{4}$ dissociation is more efficient close to the radio-frequency-powered electrode.

Matsumi et al. [53] measured the density and spatial profile of $\mathrm{SiH}$ in pure silane discharges as a function of discharge parameters such as the pressure, the silane flow, and the radio-frequency (RF) power. The fluorescence of the $\mathrm{SiH}$ molecules at $413 \mathrm{~nm}$ was induced by a nitrogen-pumped dye laser tuned at $410 \mathrm{~nm}$. SiH showed the same spatial profile as measured by Roth et al. for $\mathrm{Si}$ [52]. The $\mathrm{SiH}$ density in the ground state and in the excited $\mathrm{SiH}^{*}$ state was estimated following simultaneous LIF and optical emission measurements.

Nozaki et al. [54] evaluated the absolute density of Si and $\mathrm{SiH}$ in an HWCVD system by comparing LIF intensities with the scattered laser light by Ar atoms. The Si and $\mathrm{SiH}$ radicals were excited by a tunable Nd:YAG-pumped frequency-doubled dye laser. The ns-long pulses delivered 
by the laser system were well adapted to detect $\mathrm{SiH}$ molecules, whose excited state lifetime is as high as $0.6 \mu$ s. The detection of $\mathrm{Si}$ atoms, however, was perturbed by the fact that the lifetime of excited $\mathrm{Si}$ atoms was comparable to the duration time of the laser pulse.

As demonstrated by Hert and Jolly [55], $\mathrm{SiH}_{2}$ radicals could also be detected in silane-containing discharges using an Nd:YAG-pumped dye laser emitting at $580 \mathrm{~nm}$. The induced $\mathrm{SiH}_{2}$ fluorescence was detected at $618 \mathrm{~nm}$. From time-resolved acquisitions at $T=500 \mathrm{~K}$ and $p=9 \mathrm{~Pa}$, Hert and Jolly derived a reaction rate coefficient between $\mathrm{SiH}_{2}$ and $\mathrm{SiH}_{4}$ of $(2.3 \pm 0.5) \times 10^{-17} \mathrm{~m}^{3} \mathrm{~s}^{-1}$ molecule ${ }^{-1}$, and a surface reaction probability of $\mathrm{SiH}_{2}$ of $0.6 \pm 0.15$, instead of 0.8 as previously assumed.

\subsection{Nanoparticle detection}

\subsubsection{Laser light scattering}

Particle detection by laser light scattering (LLS) in silane discharges was first reported in 1985 by Roth and coworkers [56]. They presented a detailed study of the particle spatial distribution in an RF-powered reactor [57]. Their setup consisted of ns-pulsed Nd:YAG lasers that were frequencymultiplied up to the fourth harmonic $(\lambda=532,354$, or $266 \mathrm{~nm})$. An asymmetrical particle distribution across the inter-electrode gap was found following scattering measurements conducted at $532 \mathrm{~nm}$. Shortly after this discovery, the interest in powder growth and dynamic grew steadily and led several research groups to conduct LLS experiments. Watanabe et al. [58, 59] studied the effect of a low-frequency modulation of the RF excitation in order to reduce the powder formation. The power of the He-Ne laser they used $(\lambda=633 \mathrm{~nm})$ was only $1 \mathrm{~mW}$. With $5-\mathrm{mW}$ laser radiation at $633 \mathrm{~nm}$, Bouchoule et al. [60] measured the scattered light intensity perpendicular to the incident beam (as in the previous work) and also the scattered light intensity within a solid angle of $6^{\circ}$ with respect to the incident beam (forward scattering). This is the first extensive report on the effect of different discharge parameters such as the temperature, the silane flow, and the inter-electrode voltage on the silicon particle formation. It is also found that the temporal behavior of dusty discharges is unstable because of electron-particle interactions.

Ten years after Roth's discovery, first plasma physical/chemical models appeared. Howling et al. set up a quadrupole mass spectrometer jointly with an LLS device to demonstrate that negatively charged polysilicon particles are the precursors of larger powder particles [61], which are then detectable by LLS. In 1996, the same research group modeled experimental results obtained by LLS and derived different silicon powder formation mechanisms [62]. The experimental setup was based upon a polarized $\mathrm{Ar}^{+}$laser $(\lambda=488 \mathrm{~nm})$ and a multiple-angle detection system $\left(0^{\circ}\right.$, $45^{\circ}, 90^{\circ}, 135^{\circ}, 180^{\circ}$, and $270^{\circ}$ with respect to the incident light). The laser light polarization could be adjusted at the laser output and at the entrance of the detector. With such an experimental arrangement, they reported a particle size detection limit of $2 \mathrm{~nm}$. Despite this exceptional sensitivitythe best reported so far with LLS - the early stage of powder formation involving subnanometric particles could not be detected.

More recently, silicon nanoparticles have been detected by LLS in large-area industrial reactors, as opposed to all previous studies that were conducted in small laboratoryscale reactors (typical diameter of $20 \mathrm{~cm}$ ). With the help of a low-cost high-power $(500 \mathrm{~mW})$ compact $\mathrm{Nd}$ :YAG laser, down-stream scattering experiments were directly conducted in the exhaust line of a large-area parallel-plate reactor [63]. Using an expanded $\mathrm{Ar}^{+}$laser beam $(488 \mathrm{~nm}$, $1.5 \mathrm{~W}, 1 \mathrm{~mm} \times 25 \mathrm{~mm}$ ) and a charge-coupled device camera to detect the scattered light by powder particles, Strahm et al. [64] mapped the powder distribution between the electrodes of a large-area parallel-plate reactor. It was found that the reduction of the inter-electrode distance shifts the appearance of powder in the discharge to higher working pressures.

\subsubsection{Laser-induced particle explosive evaporation}

Laser-induced particle explosive evaporation (LIPEE) is a technique developed by Boufendi et al. [65] in 1994 to study the early stages of cluster formation, when silicon particle are still too small to be detected by LLS. During LIPEE, silicon clusters are sublimated by an intense laser beam (typically $200 \mathrm{MW} / \mathrm{cm}^{-2}$ ). Then, an optical emission spectrometer (OES) collects the light emitted by the excited states of the sublimated molecules. To prevent the plasma emission from saturating the OES detector, the laser pulse is usually shot a few milliseconds after the discharge is turned off. Silicon clusters have thus been sublimated with $25-\mathrm{mJ} 20$-nslong pulses of a XeCl* excimer laser $(\lambda=308 \mathrm{~nm})$ or with $15-\mathrm{mJ}$ pulses of an Nd:YAG laser $(\lambda=1064 \mathrm{~nm})$.

The kinetics of powder formation have been derived from time-resolved LIPEE measurements. For the first time, three distinct steps were evidenced: nucleation of crystallites, crystallites coalescence, and molecular sticking onto larger particles. For comparison, LLS is only able to detect the second and third steps in the particle growth mechanism. Transmission electron microscopy measurements confirmed the ability of LIPEE to detect the transition between these three particle growth steps [66]. LIPEE was further developed to study the radial distribution of crystallites in parallel-plate discharges and the influence of the reactor temperature on the formation of silicon crystallites in $\mathrm{Ar}-\mathrm{SiH}_{4}$ discharges. It has been demonstrated that lower reactor temperatures 
Table 2 Laser-based characterization techniques applied in TF photovoltaics

\begin{tabular}{llll}
\hline Technique & Measured physical quantity & Deduced material properties & References \\
\hline $\begin{array}{lll}\text { Micro-Raman spectroscopy } \\
\text { Photoluminescence spectroscopy }\end{array}$ & $\begin{array}{l}\text { Inelastic scattering } \\
\text { Radiative recombination }\end{array}$ & Phase composition & Donor and acceptor \\
binding energies & [68-71,73, 74] \\
$\begin{array}{l}\text { Time-resolved photoluminescence } \\
\text { Photothermal deflection spectroscopy }\end{array}$ & Photoluminescence decay time & Carrier dynamics & Sub-bandgap absorption, \\
& Laser beam deflections & defect densities & [67, 75, 79, 80] \\
Light-beam-induced current & Photocurrent & Homogeneity & [67, 86, 87] \\
Internal photoemission & Photocurrent & Conduction band discontinuity & [88, 89] \\
Photoreflectance spectroscopy & Reflectance & Bandgap energies & [90] \\
\hline
\end{tabular}

promote crystallite formation, which in turn rapidly leads to the growth of coarser particles.

\section{Laser-based characterization methods for TF photovoltaics}

Lasers have played a significant role in the characterization of PV-relevant materials. An exhaustive review of all material properties that have been investigated by laserbased methods would go beyond the scope of the present work. The authors merely wish to provide a brief overview of characterization techniques that implement lasers. They are summarized in Table 2. For a detailed description of well-established techniques such as micro-Raman and photoluminescence spectroscopies, the authors refer to literature $[67,68]$.

In TF Si technologies, Raman spectra are routinely evaluated to determine the degree of crystallinity of $\mu \mathrm{c}-\mathrm{Si}: \mathrm{H}$ films [69-71]. The structure of device-grade $\mu \mathrm{c}-\mathrm{Si}: \mathrm{H}$ films consists of conical conglomerates of Si nanocrystals, where the micrometer-sized conglomerates and the nanocrystal grain boundaries are passivated by a-Si:H. The amorphous phase is associated with a broad Raman peak centered around $480 \mathrm{~cm}^{-1}$, while the sharp peak centered around $520 \mathrm{~cm}^{-1}$ is characteristic of the c-Si phase. Micro-Raman spectroscopy has also contributed to better understand the complex nature of CIGS alloys. The bandgap of $\mathrm{Cu}(\mathrm{In}, \mathrm{Ga}) \mathrm{Se}_{2}$ increases as $\mathrm{Ga}$ is added to replace In. Record efficiencies are realized at $\mathrm{Ga} /(\mathrm{Ga}+\mathrm{In})$ ratios of 0.3 [72]. The $\mathrm{Cu}$ content of such high-efficiency solar cells may vary remarkably. In addition to the chalcopyrite mode centered around $177 \mathrm{~cm}^{-1}$, Cu-rich CIGS exhibits a mode centered around $260 \mathrm{~cm}^{-1}$, which is assigned to a detrimental highlyconductive $\mathrm{Cu}_{2-x}$ Se phase $[73,74]$. Irrespective of the TF PV technology, Raman spectra must be interpreted in light of the optical penetration depth of the laser within the sample. $\mathrm{Ar}^{+}, \mathrm{He}-\mathrm{Ne}$, and frequency-doubled Nd:YAG lasers are common excitation sources found in micro-Raman spectrometers.

The photoluminescence spectra of TF PV materials present rather broad spectral features, and their interpretation is generally not straightforward. Furthermore, the high nonradiative recombination rates often require measurements to be performed at cryogenic temperatures. In spite of it all, various photoluminescence studies have contributed to unveil the nature of radiative recombinations in TF PV materials [75-78].

Depending on the TF technology, the photoluminescence decays in a ps to ns time scale $[75,79,80]$. These short decay times are typically resolved with a mode-locked laser and provide some insight into carrier dynamics. To a certain extent, the photoluminescence decay time of TF solar cells is correlated to device performances [79, 80].

At room temperature, nonradiative defect-mediated recombinations dominate in a-Si: $\mathrm{H}, \mathrm{CdTe}$, and CIGS devices. Structural defects are the source of the unwanted recombination centers in Si films. They are responsible for a low level of absorption below the bandgap. This sub-bandgap absorption cannot be measured with a traditional visible-near infrared spectrometer but instead requires a sensitive technique such as photothermal deflection spectroscopy [81]. In this technique, a modulated monochromatic beam is focused onto a sample that is immersed in a transparent liquid. Upon absorption of the monochromatic beam by the sample and diffusion of the generated heat into the liquid, a refractive index gradient builds up in the immediate vicinity of the sample and deflects a probe laser beam. The laser deflections are related to the absorption in the sample. The sub-bandgap absorption is related to the defect density [82, 83]. In photothermal deflection setups, a He-Ne laser is often chosen as probe beam due to its high beam quality and stability.

The commonly-reported current-voltage characteristic of a PV module gives a global view of its performance. A spatially resolved nondestructive assessment of the module performance can be undertaken with light-beam-induced current or thermographic systems [67, 84-86]. The light-beam- 
induced current technique (LBIC) maps the spatial distribution of the photocurrent in the module. Employed under short-circuit current conditions, it consists in recording the photocurrent while sequentially illuminating-typically with a laser beam-localized areas of the module under study. An LBIC analysis can, e.g., improve the yield of a production line through troubleshooting of the baseline process [87]. Multi-wavelength LBIC systems are even capable of selectively studying one junction within a multijunction device [86].

Further specialized laser-based characterization techniques are reported in literature such as internal photoemission or photoreflectance spectroscopy. Internal photoemission consists in amplifying and measuring the external photocurrent of a heterojunction under optical pumping. After plotting the current versus the photon energy, one determines the threshold related to the conduction band discontinuity. Early experiments were limited to pumping from the top of the valence band in one material to the bottom of the conduction band in the other. With the development of highpower widely tunable infrared free-electron laser sources, it has become possible to directly pump a heterojunction interface across its conduction band discontinuity [88]. The free-electron laser-based internal photoemission technique was applied, e.g., to investigate the conduction band discontinuity of a CdS/CdTe interface [89].

Photoreflectance spectra are acquired during pump-probe experiments. While a modulated pump laser beam excites electron-hole pairs in a sample, the wavelength-dependent reflectance of the sample is measured with a widely tunable probe source. Instead of a laser beam, an AC voltage is often applied as modulating source. The derivative-like features of photoreflectance spectra correspond to interband transitions in the sample [90].

Finally, various lasers are applied to measure the angular distribution of scattered light on textured surfaces. The angular resolved scattering is then introduced into optical models to simulate the performances of TF solar cells [91, 92].

\section{Conclusions}

A wide range of laser-based methods are applied to characterize films in the development stage of PV modules. Furthermore, lasers have become key components in the manufacture of TF PV modules. They are applied as scribing tools to serially interconnect the individual cells of a TF PV module. While cells that are grown in a superstrate configuration are routinely processed by laser scribing systems, the monolithic serial interconnection of cells grown in a substrate configuration presents some difficulties. Other laser-based fabrication processes such as pulsed laser deposition and laser-induced crystallization are still marginal in the field of TF photovoltaics.
During deposition of Si thin films, laser systems have proven to be the only tools capable of detecting a wide range of chemical species in a nonintrusive manner. Silane $\left(\mathrm{SiH}_{4}\right)$, silane radicals $\left(\mathrm{SiH}_{3}, \mathrm{SiH}_{2}, \mathrm{SiH}, \mathrm{Si}\right)$, and $\mathrm{Si}$ nanoparticles have all been monitored in situ in PECVD systems. While a considerable amount of effort has been undertaken to better understand the physics of chemical reactors, correlations between the plasma composition and TF properties are still lacking. In the authors' opinion, such correlations should be the target of future research.

\section{References}

1. R.M. Swanson, Prog. Photovolt. 14(5), 443 (2006)

2. Photon Int. 170-206 (2009)

3. D. Bonnet, Thin Solid Films 361, 547 (2000)

4. S. Nakano, T. Matsuoka, S. Kiyama, H. Kawata, N. Nakamura, Y. Nakashima, S. Tsuda, H. Nishiwak, M. Ohnishi, I. Nagaoka, Y. Kuwano, Jpn. J. Appl. Phys. 25(12), 1936-1943 (1986)

5. K. Brecl, M. Topic, F. Smole, Prog. Photovolt. 13(4), 297 (2005)

6. A.G. Aberle, Thin Solid Films 517(17), 4706 (2009)

7. A.V. Shah, H. Schade, M. Vanecek, J. Meier, E. Vallat-Sauvain, N. Wyrsch, U. Kroll, C. Droz, J. Baillat, Prog. Photovolt., Res. Appl 12, 113 (2004). doi:10.1002/pip.533

8. A.D. Compaan, I. Matulionis, S. Nakade, Opt. Lasers Eng. 34(1), $15(2000)$

9. S. Haas, A. Gordijn, H. Stiebig, Prog. Photovolt. 16(3), 195 (2008)

10. S. Haas, G. Schope, C. Zahren, H. Stiebig, Appl. Phys. A, Mater. Sci. Process. 92(4), 755 (2008)

11. C. Molpeceres, S. Lauzurica, J.L. Ocana, J.J. Gandia, L. Urbina, J. Carabe, J. Micromech. Microeng. 15(6), 1271 (2005)

12. C. Molpeceres, S. Lauzurica, J.J. Garcia-Ballesteros, M. Morales, S. Fernandez-Robledo, J.L. Ocana, J.J. Gandia, J. Carabe, F. Villar, J. Escarre, J. Bertomeu, J. Andreu, Appl. Surf. Sci. 254(4), 1115 (2007)

13. J. Bohland, A. McMaster, S. Henson, J. Hanak, Specific PVMaT R\&D in CdTe product manufacturing-final subcontract report, March 2003. Subcontractor report NREL/SR-520-35177, National Renewable Energy Laboratory, 1617 Cole Boulevard, Golden, CO 80401-3393, January 2004

14. D. Ruthe, K. Zimmer, T. Hoche, Appl. Surf. Sci. 247(1-4), 447 (2005)

15. J. Hermann, M. Benfarah, G. Coustillier, S. Bruneau, E. Axente, J.F. Guillemoles, M. Sentis, P. Alloncle, T. Itina, Appl. Surf. Sci. 252(13), 4814 (2006)

16. D. Bäuerle, Laser Processing and Chemistry, 3rd edn. (Springer, Berlin, 2000)

17. P. Dittrich, R. Bartlome, G. Montemezzani, P. Gunter, Appl. Surf. Sci. 220(1-4), 88 (2003)

18. F. Kessler, D. Herrmann, M. Powalla, Thin Solid Films 480, 491 (2005)

19. A. Vijh, X. Yang, W. Du, X. Deng, Sol. Energy Mater. Sol. Cells 90(16), 2657 (2006)

20. High-precision light-market survey on laser scribers for monolithic integration of thin-film modules. Photon Int. 258-272 (2008)

21. R. Bartlome, Y. Sinquin, S.A. Meyer, C. Ballif, A. Raible, Versatile thin-film photovoltaic laser scribing system, in Proc. of the 24th European Photovoltaic Solar Energy Conference, Hamburg, Germany (2009), pp. 2854-2855

22. R.B. Bergmann, Appl. Phys. A, Mater. Sci. Process. 69(2), 187 (1999) 
23. O. Nast, S.R. Wenham, J. Appl. Phys. 88(1), 124 (2000)

24. M.A. Green, P.A. Basore, N. Chang, D. Clugston, R. Egan, R. Evans, D. Hogg, S. Jarnason, M. Keevers, P. Lasswell, J. O'Sullivan, U. Schubert, A. Turner, S.R. Wenham, T. Young, Sol. Energy 77(6), 857 (2004)

25. G. Andra, J. Bergmann, F. Falk, E. Ose, H. Stafast, Phys. Status Solidi A, Appl. Res. 166(2), 629 (1998)

26. A.A.D.T. Adikaari, S.R.P. Silva, Nano 3(3), 117 (2008)

27. K. Yamamoto, A. Nakashima, T. Suzuki, M. Yoshimi, H. Nishio, M. Izumina, Jpn. J. Appl. Phys. 33(12B), L1751 (1994)

28. B.K. Nayak, M.C. Gupta, Appl. Phys. A, Mater. Sci. Process. 89, 663 (2007)

29. T.H. Her, R.J. Finlay, C. Wu, E. Mazur, Appl. Phys. A, Mater. Sci. Process. 70(4), 383 (2000)

30. K. Matsubara, P. Fons, K. Iwata, A. Yamada, K. Sakurai, H. Tampo, S. Niki, Thin Solid Films 431, 369 (2003)

31. S.K. Pandey, U. Tiwari, R. Raman, C. Prakash, V. Krishna, V. Dutta, K. Zimik, Thin Solid Films 473(1), 54 (2005)

32. P.F. Luo, G.S. Jiang, C.F. Zhu, Chin. J. Chem. Phys. 22(1), 97 (2009)

33. M. Hanabusa, Z.X. Liu, N. Nakamura, H. Hasegawa, Nucl. Instrum. Methods Phys. Res., Sect. B, Beam Interact. Mater. Atoms 121(1-4), 367 (1997)

34. J.P.M. Hoefnagels, Y. Barrell, W.M.M. Kessels, M.C.M. van de Sanden, J. Appl. Phys. 96(8), 4094 (2004)

35. N. Itabashi, N. Nihsiwaki, M. Magane, S. Naito, T. Goto, A. Matsuda, C. Yamada, E. Hirota, Jpn. J. Appl. Phys. 29(3), L505 (1990)

36. P.B. Davies, N.A. Isaacs, S.A. Johnson, D.K. Russell, J. Chem. Phys. 83(5), 2060 (1985)

37. C. Yamada, E. Hirota, Phys. Rev. Lett. 56(9), 923 (1986)

38. J.U. White, J. Opt. Soc. Am. 32(5), 285 (1942)

39. D. Herriott, H. Kogelnik, R. Kompfner, Appl. Opt. 3(4), 523 (1964)

40. R. Bartlome, M. Baer, M.W. Sigrist, Rev. Sci. Instrum. 78(1), 013110 (2007)

41. M.W. Sigrist, R. Bartlome, D. Marinov, J.M. Rey, D.E. Vogler, H. Wachter, Appl. Phys. B, Lasers Opt. 90(2), 289 (2008)

42. Y. Sumiyoshi, K. Tanaka, T. Tanaky, Appl. Surf. Sci. 79/80, 471 (1994)

43. R. Bartlome, A. Feltrin, C. Ballif, Appl. Phys. Lett. 94, 201501 (2009)

44. M.D. Wheeler, S.M. Newman, A.J. Orr-Ewing, M.N.R. Ashfold, J. Chem. Soc. Faraday Trans. 94(3), 337 (1998)

45. G. Berden, R. Peeters, G. Meijer, Int. Rev. Phys. Chem. 19(4), 565 (2000)

46. V. Sanders, Appl. Opt. 16(1), 19 (1977)

47. J.M. Herbelin, J.A. McKay, M.A. Kwok, R.H. Ueunten, D.S. Urevig, D.J. Spencer, D.J. Benard, Appl. Opt. 19(1), 144 (1980)

48. B.A. Paldus, A.A. Kachanov, Can. J. Phys. 83, 975 (2005)

49. W.M.M. Kessels, J.P.M. Hoefnagels, M.H.H. Boogaarts, D.C. Schram, M.C.M. van de Sanden, J. Appl. Phys. 89(4), 2065 (2001)

50. T. Nagai, A.H.M. Smets, M. Kondo, J. Non-Cryst. Solids 354, 2096 (2008)

51. F. Grangeon, C. Monard, J.-L. Dorier, A.A. Howling, Ch. Hollenstein, D. Romanini, N. Sadeghi, Plasma Sources Sci. Technol. 8, 448 (1999)

52. R.M. Roth, K.G. Spears, G. Wong, Appl. Phys. Lett. 45(1), 28 (1984)

53. Y. Matsumi, T. Hayashi, H. Yoshikawa, S. Komiya, J. Vac. Sci. Technol. A 4(3), 1789 (1986)

54. Y. Nozaki, K. Kongo, T. Miyazaki, M. Kitazoe, K. Horii, H. Umemoto, A. Masuda, H. Matsumura, J. Appl. Phys. 88(9), 5437 (2000)

55. M. Hertl, J. Jolly, J. Phys. D, Appl. Phys. 33, 381 (2000)
56. R.M. Roth, K.G. Spears, G.D. Stein, G. Wong, Appl. Phys. Lett. 46(3), 253 (1985)

57. K.G. Spears, T.J. Robinson, R.M. Roth, IEEE Trans. Plasma Sci. 14(2), 179 (1986)

58. Y. Watanabe, M. Shiratani, Y. Kubo, I. Ogawa, S. Ogi, Appl. Phys. Lett. 53(14), 1263 (1988)

59. Y. Watanabe, J. Phys. D, Appl. Phys. 39, R329 (2006)

60. A. Bouchoule, A. Plain, L. Boufendi, J.Ph. Blondeau, C. Laure, J. Appl. Phys. 70(4), 1991-2000 (1991)

61. A.A. Howling, C. Courteille, J.-L. Dorier, L. Sansonnens, Ch. Hollenstein, Pure Appl. Chem. 68(5), 1017 (1996)

62. C. Courteille, Ch. Hollenstein, J.-L. Dorier, P. Gay, W. Schwarzenbach, A.A. Howling, E. Bertran, G. Viera, R. Martins, A. Macarico, J. Appl. Phys. 80(4), 2069 (1996)

63. R. Bartlome, B. Strahm, A. Feltrin, C. Ballif, in Proc. of the 34th IEEE Photovoltaic Specialist Conference, Philadelphia, PA, June 7-12, 2009, paper 103.

64. B. Strahm, C. Hollenstein, Powder formation in $\mathrm{SiH}_{4}-\mathrm{H}_{2}$ discharge in large area capacitively-coupled reactor: a study of the combined effect of the inter-electrode distance and pressure. J. Appl. Phys. (2009 in print)

65. L. Boufendi, J. Hermann, A. Bouchoule, B. Dubreuil, E. Stoffels, W.W. Stoffels, M.L. de Giorgi, J. Appl. Phys. 76(1), 148 (1994)

66. L. Boufendi, A. Bouchoule, Plasma Sources Sci. Technol. 3, 262 (1994)

67. K. Durose, S.E. Asher, W. Jaegermann, D. Levi, B.E. McCandless, W. Metzger, H. Moutinho, P.D. Paulson, C.L. Perkins, J.R. Sites, G. Teeter, M. Terheggen, Prog. Photovolt. 12(2-3), 177 (2004)

68. G. Gouadec, P. Colomban, Prog. Cryst. Growth Charact. Mater. 53(1), 1 (2007)

69. E. Bustarret, M.A. Hachicha, M. Brunel, Appl. Phys. Lett. 52(20), 1675 (1988)

70. M. Tzolov, F. Finger, R. Carius, P. Hapke, J. Appl. Phys. 81(11), 7376 (1997)

71. E. Vallat-Sauvain, C. Droz, F. Meillaud, J. Bailat, A. Shah, C. Ballif, J. Non-Cryst. Solids 352(9-20), 1200 (2006)

72. I. Repins, M.A. Contreras, B. Egaas, C. DeHart, J. Scharf, C.L. Perkins, B. To, R. Noufi, Prog. Photovolt. 16(3), 235 (2008)

73. H. Miyazaki, R. Mikami, A. Yamada, M. Konagai, J. Phys. Chem. Solids 64(9-10), 2055 (2003)

74. W. Witte, R. Kniese, M. Powalla, Thin Solid Films 517(2), 867 (2008)

75. S. Komuro, Y. Aoyagi, Y. Segawa, S. Namba, A. Masuyama, D. Kruangam, H. Okamoto, Y. Hamakawa, J. Appl. Phys. 58(2), 943 (1985)

76. G.Z. Yue, D.X. Han, D.L. Williamson, J. Yang, K. Lord, S. Guha, Appl. Phys. Lett. 77(20), 3185 (2000)

77. M. Wagner, I. Dirnstorfer, D.M. Hofmann, M.D. Lampert, F. Karg, B.K. Meyer, Phys. Stat. Sol. A, Appl. Res. 167(1), 131 (1998)

78. I. Dirnstorfer, M. Wagner, D.M. Hofmann, M.D. Lampert, F. Karg, B.K. Meyer, Phys. Stat. Sol. A, Appl. Res. 168(1), 163 (1998)

79. W.K. Metzger, D. Albin, D. Levi, P. Sheldon, X. Li, B.M. Keyes, R.K. Ahrenkiel, J. Appl. Phys. 94(5), 3549 (2003)

80. S. Shirakata, T. Nakada, Thin Solid Films 515(15), 6151 (2007)

81. W.B. Jackson, N.M. Amer, A.C. Boccara, D. Fournier, Appl. Opt. 20(8), 1333 (1981)

82. W.B. Jackson, N.M. Amer, Phys. Rev. B 25(8), 5559 (1982)

83. N. Wyrsch, F. Finger, T.J. McMahon, M. Vanecek, J. Non-Cryst. Solids 137, 347 (1991)

84. O. Breitenstein, M. Langenkamp, F. Altmann, D. Katzer, A. Lindner, H. Eggers, Rev. Sci. Instrum. 71(11), 4155 (2000)

85. O. Breitenstein, J.P. Rakotoniaina, A.S.H. van der Heide, J. Carstensen, Prog. Photovolt. 13(8), 645 (2005)

86. P. Vorasayan, T.R. Betts, A.N. Tiwari, R. Gottschag, Sol. Energy Mater. Sol. Cells 93(6-7), 917 (2009)

87. K. Kushiya, Thin Solid Films 387(1-2), 257 (2001) 
88. C. Coluzza, E. Tuncel, J.L. Staehli, P.A. Baudat, G. Margaritondo, J.T. McKinley, A. Ueda, A.V. Barnes, R.G. Albridge, N.H. Tolk, D. Martin, F. Morier-Genoud, C. Dupuy, A. Rudra, M. Ilegems, Phys. Rev. B 46(19), 12834 (1992)

89. K. Nishi, H. Ohyama, T. Suzuki, T. Mitsuyu, T. Tomimasu, Appl. Phys. Lett. 70(26), 3585 (1997)

90. S. Theodoropoulou, D. Papadimitriou, A.G. Mamalis, D.E. Manolakos, R. Klenk, M.C. Lux-Steiner, Semicond. Sci. Technol. 22, 933 (2007)
91. J. Krc, M. Zeman, O. Kluth, E. Smole, M. Topic, Thin Solid Films 426(1-2), 296 (2003)

92. D. Domine, F.-J. Haug, C. Battaglia, C. Ballif, J. Appl. Phys. (2009 in print)

93. J.P.M. Hoefnagels, A.A.E. Stevens, M.G.H. Boogaarts, W.M.M. Kessels, M.C.M. van de Sanden, Chem. Phys. Lett. 360, 189 (2002) 